\title{
How local depositional conditions control marine sedimentary pyrite sulfur isotopes: a framework integrating bulk and micro-scale SIMS analyses
}

DAVID A. FIKE ${ }^{1}$, JENNIFER HOUGHTON ${ }^{2}$, CLIVE JONES $^{2}$, ROGER N BRYANT ${ }^{3}$, DANIELE SCARPONI ${ }^{4}$, MR. VIRGIL PASQUIER, PHD ${ }^{5}$, ITAY HALEVY ${ }^{5}$ AND ROBERT ALLER $^{6}$

${ }^{1}$ Washington University in St Louis

${ }^{2}$ Washington University

${ }^{3}$ University of Chicago

${ }^{4}$ University of Bologna

${ }^{5}$ Weizmann Institute of Science

${ }^{6}$ Stonybrook University

Presenting Author: dfike@levee.wustl.edu

Variations in the isotopic composition of sulfur in sedimentary pyrite $\left(\delta^{34} S_{\text {pyr }}\right)$ are often used to reconstruct global sulfur biogeochemical cycling and Earth's surface oxidation state over Earth history. Recent work, however, has shown that $\delta^{34} \mathrm{~S}_{\mathrm{pyr}}$ is strongly impacted by local depositional conditions, which both confounds attempts to reconstruct global sulfur cycling and has the potential to provide a new proxy for investigating and reconstructing local paleoenvironmental conditions. Here we present chemostratigraphic records of bulk sedimentary $\delta^{34} \mathrm{~S}_{\mathrm{pyr}}$ in a detailed sedimentological and sequence stratigraphic framework from a range of Pleistocene to modern sediments in diverse depositional environments that reflect deposition under varying sedimentation rates, organic carbon loading, and degrees of physical reworking by tides, storms, and ocean currents. To complement bulk sedimentary $\delta^{34} \mathrm{~S}_{\mathrm{pyr}}$ data, we additionally collected micron-scale $\delta^{34} \mathrm{~S}_{\mathrm{pyr}}$ data via secondary ion mass spectrometry (SIMS) from populations of individual pyrites that together give rise to the bulk $\delta^{34} \mathrm{~S}_{\text {pyr }}$ values in any given sample. These SIMS results identify discrete populations of pyrites with distinctive isotopic signatures within these sediment samples. The relative abundance of these different populations is controlled by depositional environment and corresponding syndepositional processes that regulate continued pyrite formation within the porewaters. In turn, it is the relative abundance of these different populations that determines the resulting bulk $\delta^{34} \mathrm{~S}_{\mathrm{pyr}}$ value within the sediments. These results demonstrate the value of combined bulk and microscale analysis in investigating $\delta^{34} \mathrm{~S}_{\mathrm{pyr}}$ records and highlight the role of local conditions in controlling sedimentary $\delta^{34} \mathrm{~S}_{\mathrm{pyr}}$ records. Moreover, this work also illustrates how these isotopic data can be used to reconstruct key parameters of the sedimentary environment that might not be otherwise accessible, especially in deep-time strata. 